\title{
Obtaining Maximal Stability with a Septal Extension Technique in East Asian Rhinoplasty
}

\author{
Jae Yong Jeong \\ PLUS Aesthetic Surgery Clinic, Daejeon, Korea
}

Recently, in Korea, the septal extension graft from the septum or rib has become a common method of correcting a small or short nose. The success rate of this method has led to the blind faith that it provides superior tip projection and definition, and to the failure to notice its weaknesses. Even if there is a sufficient amount of cartilage, improper separation or fixation might waste the cartilage, resulting in an inefficient operation. Appropriate resection and effective fixation are essential factors for economical rhinoplasty. The septal extension graft is a remarkable procedure since it can control the nasal tip bidirectionally and three dimensionally. Nevertheless, it has a serious drawback since resection is responsible for septal weakness. Safe resection and firm reconstruction of the framework should be carried out. Operating on the basis of the principle of "safe harvest" and rebuilding the structures is important. Further, it is important to learn several techniques to manage septal weakness, insufficient cartilage quantity, and failure of the rigid frame during the surgery.

Keywords Rhinoplasty / Nasal septum / Ear cartilage / Nose deformities, Acquired

Correspondence: Jae Yong Jeong PLUS Aesthetic Surgery Clinic, 203 Daedeok-daero, Seo-gu, Daejeon 302-829, Korea Tel: +82-42-486-6543 Fax: +82-42-483-6543 E-mail: dogearjeong@hotmail.com

I would like to express my sincere gratitude to Dr. Sangmun Choi for his linguistic assistance in the preparation of this manuscript.

No potential conflict of interest relevant to this article was reported.

\section{IMPORTANCE OF STABILITY}

Dr. Byrd et al. [1] introduced the septal extension graft 15 years ago, and many Korean plastic surgeons have practiced this technique since then $[2,3]$. Because the septal extension graft is an invasive procedure, cartilage resection can lead to septal weakness. Furthermore, the loss of dorsal strut support might cause nasal collapse or saddle nose deformity, and the loss of caudal strut support might decrease the tip projection or deviate the tip complex.

Septal extension depends on the patient's L-strut strength, and thus, the original stability is the most important factor. Deviation of the L-strut, the shape and size of the harvested septum, and the fixation methods are other direct factors that affect the results of the rhinoplasty. Indirect factors that affect the results of the operation include nasal envelope characteristics, previous operation history, lower lateral cartilage and surrounding abutments, and the strength of the depressor septi nasi.

\section{Histological and biomechanical characteristics of the nasal septum}

The nasal septum is composed of hyaline cartilage that is used as a supporting or contouring material. It consists of a few chondrocytes and a large number of intercellular substances, primarily formed by regularly distributed collagen fibers. On the other hand, the ear cartilage has many chondrocytes but little intercellular substance and lacks collagen fibers [4]. These features define the histological and morphological characteristics and lead to a difference in the degree of stiffness, curvature, strength, and elasticity. Understanding these characteristics makes it easier to

Copyright (C) 2014 The Korean Society of Plastic and Reconstructive Surgeons

This is an Open Access article distributed under the terms of the Creative Commons Attribution Non-Commercial License (http://creativecommons.org/

licenses/by-nc/3.0/) which permits unrestricted non-commercial use, distribution, and reproduction in any medium, provided the original work is properly cited.

www.e-aps.org 
choose the type of cartilage to use for the nose correction and helps in the handling of the cartilage (Table 1).

Nasal growth peaks at 13.1 years and matures at 15.8 years in $98 \%$ of the female population. Further, it peaks at 14.7 years and matures at 16.9 years in $98 \%$ of the male population. It is recommended that septal intervention be conducted after this maturation period [5].

As with other cartilage, the septum also shows age-related changes. While the amount of hydroxyproline, the main component, does not change substantially, that of glycosaminoglycan (GAG) decreases significantly. If the patient is old, the equilibrium modulus decreases and the hydraulic permeability increases; these changes are related to the calcification or ossification of the cartilage. Therefore, when operating on the elderly, the surgeon should be aware that the cartilage might crack while it is being manipulated, and appropriate care should thus be exercised [6].

\section{Is the Korean septum smaller than the Westerners' septum?} In general, the East Asian septal cartilage is believed to be relatively smaller than its Western counterpart. Kim et al. $[7,8]$ reported that the height and length of the septal cartilage of Korean cadavers they examined were, on average, $22.1 \mathrm{~mm}$ and $28 \mathrm{~mm}$, respectively. Hwang et al. [9] reported the mean length and height of septal cartilage as $33.1 \pm 5.3$ and $29.9 \pm 4.7 \mathrm{~mm}$, respectively. The thickest part was the septal base anterior to the vomer, which was approximately $2.19-3.03 \mathrm{~mm}$ in size, and the thinnest part, at $1.03-1.22 \mathrm{~mm}$, was just above the septal base at $20 \%$ of the septal height. Meanwhile, de Pochat et al. [10] stated that the average length and height of the septum of a Brazilian sample was $35.4 \mathrm{~mm}$ and $32.5 \mathrm{~mm}$, respectively. The thickest part was $1.7 \mathrm{~mm}$ and the thinnest part, $1.04 \mathrm{~mm}$. In a study by Mowlavi et al. [11], the thickest part was $2.7 \mathrm{~mm}$ and the thinnest, 1.3 $\mathrm{mm}$. Although the above studies involved only a small number of specimens, there does not appear to be strong supporting evidence that the Korean septum is significantly smaller than the Western septum (Table 2) [8-11]. However, Korean surgeons might believe that their patients' septum size is relatively small, since a large amount of cartilage is required for tip projection in East Asians. In the author's personal experience during 9 years of rhinoplasty, there is a wide range of variation in the septum size among patients.

\section{Operative factors related to the stability of the septal ex- tension graft \\ What harvesting method should we choose?}

Similar to other operations, the harvesting process should be based on the "safe harvest" concept. False harvesting methods can lead to traumatic results on both the donor site and the grafted site. Harvesting methods can be divided into two types: a division method using a $\mathrm{D}$-knife and a resection method using a swivel knife. The division technique using a $\mathrm{D}$-knife divides the cartilage at the bony-cartilaginous junction and is widely used by skilled surgeons. It can yield a significant amount of cartilage that is located inferiorly to the vomerine groove. A swivel knife is used for the resection of the cartilage; however, it can cause cartilage loss due to inaccurate separation. Furthermore, it is difficult to harvest a large amount of tissue and there is a

Table 1. Histological characteristics of each cartilage and their usage

\begin{tabular}{|c|c|c|c|c|c|c|c|c|}
\hline Cartilage & Types & $\begin{array}{l}\text { Chondrocytes } \\
\text { (cellularity) }\end{array}$ & $\begin{array}{l}\text { Intercellular } \\
\text { substance } \\
\text { (matrix) }\end{array}$ & $\begin{array}{l}\text { Collagen } \\
\text { fibers }\end{array}$ & $\begin{array}{l}\text { Elastic } \\
\text { fibers }\end{array}$ & $\begin{array}{c}\text { Distribution } \\
\text { of fibers }\end{array}$ & Supporting & $\begin{array}{l}\text { Adding and } \\
\text { filling }\end{array}$ \\
\hline Ear & Elastic & +++ & + & - & ++ & Irregular & Carefully used & Good \\
\hline Septum & Hyaline & + & +++ & +++ & - & Regular & Ideal & Ideal \\
\hline Ala & Hyaline & + & +++ & +++ & - & Regular & Not recommended & Good \\
\hline Rib & Hyaline & + & +++ & +++ & - & Regular & Ideal & Carefully used \\
\hline
\end{tabular}

\section{Table 2. Studies on the measurement of human septal cartilage}

\begin{tabular}{|c|c|c|c|c|c|c|}
\hline Author & No. of specimen & $\begin{array}{l}\text { Length of septal } \\
\text { cartilage }(\mathrm{mm})\end{array}$ & $\begin{array}{l}\text { Height of septal } \\
\text { cartilage }(\mathrm{mm})\end{array}$ & $\begin{array}{l}\text { Surface area } \\
\left(\mathrm{mm}^{2}\right)\end{array}$ & $\begin{array}{l}\text { Thickest portion } \\
(\mathrm{mm})\end{array}$ & $\begin{array}{l}\text { Thinnest portion } \\
(\mathrm{mm})\end{array}$ \\
\hline Kim et al. (2006) [8] & 10 (Korean cadavers) & 28 & 22.1 & $\begin{array}{c}\text { 432-910 } \\
\text { (average 627.2) }\end{array}$ & - & - \\
\hline Hwang et al. (2010) [9] & 14 (Korean cadavers) & $33.1 \pm 5.3$ & $29.9 \pm 4.7$ & - & $\begin{array}{l}2.19-3.03 \\
\text { (septal base) }\end{array}$ & $\begin{array}{c}0.74-0.97 \text { (at } 20 \% \text { of } \\
\text { the septal height) }\end{array}$ \\
\hline de Pochat et al. (2011) [10] & 14 (Brazilian cadavers) & 35.14 (average) & 32.5 & 933.11 & 1.71 & 1.04 \\
\hline Mowlavi et al. (2006) [11] & 11 (Caucasian cadavers) & $31 \pm 4.0$ (average) & $26 \pm 3.0$ & - & 2.7 & $\begin{array}{l}1.3 \pm 0.2 \text { (along the } \\
\text { central portion) }\end{array}$ \\
\hline
\end{tabular}


possibility of damaging the surrounding tissue such as mucosa. Since it is used occasionally, surgeons should choose a division method of their preference. This author personally favors the division method using the $\mathrm{D}$-knife rather than resection [12].

What amount of cartilage should be harvested? That is, what amount of L-strut should remain?

According to Kim et al. [7,8], if the remaining width of the Lstrut is $10 \mathrm{~mm}$, the available septal size that can be harvested is, on average, $12.1 \mathrm{~mm} \times 18.0 \mathrm{~mm}$ in Koreans. Byrd preferred a graft width of 5-6 mm, and Gruber recommended a graft width of $10 \mathrm{~mm}$. In the East Asian nose, with a higher degree of extension and tip projection, a correspondingly larger and more rigid graft is required. If the harvested septal graft is small, a direct septal extension graft or additional harvesting of the other cartilages is necessary.

There is a more important factor than achieving a large amount of cartilage: the stability of the remaining L-strut. For greater strength of the L-strut, a harvesting method is recommended as described in Fig. 1. One aspect requiring caution during the harvest is that the cutting line should be in a curved shape between the dorsal and the caudal cutting line. In particular, the inferior portion of the keystone area cartilage should remain in order to prevent a saddle nose deformity. Mau et al. [13] noted that the L-strut can survive in the following circumstances: a large width of the L-strut, a long overlapping junction beneath the keystone, and a remnant of the small cartilage block at the bony-cartilage junction of the septum. The preservation of a small cartilage block is more resistive to stress and trauma, which contributes to stability. On the other hand, the available cartilage that can be harvested is reduced. The surgeon should make a flexible decision in several situations.

A recommendation of the width of the $\mathrm{L}$-strut to leave varies among surgeons: Sheen recommends $15 \mathrm{~mm}$; Daniel, 7-8 mm; and Tebbetts, 5-10 mm. The surgeon should always decide on the L-strut size depending on the septum thickness, degree of deviation, and rigidity before harvesting the septum. Furthermore, the surgeon should be aware of the septal differences among patients and be flexible in dealing with the given situation.

I prefer leaving at least 5-6 $\mathrm{mm}$ of the septum of the caudal portion depending on the strength and rigidity. It is preferable to leave at least $10 \mathrm{~mm}$ at the bony-cartilage junction, which is beneath the keystone area. Resecting more of the caudal portion of the septal cartilage than the cephalic portion does not help to reinforce the L-strut stability on the caudal septum in East Asians since the caudal septum is thin and weak. Therefore, harvested septum should be used for strengthening or reinforcing the caudal septum because caudal septum in Asian is thin and weak.

\section{Intraoperative evaluation of intactness of the remaining L-strut and its reinforcement}

To check the remaining septal L-strut stability, intraoperative stability tests (vertical stability test and horizontal stability test) should be performed. For these stability tests, the caudal strut should be grasped with forceps and mildly shaken vertically and horizontally. If the vertical test is carried out during the operation, the L-strut tends to bend or deviate to one side (Fig. 2) $[14,15]$. However, with various suture techniques, stability and straightness can be achieved. Gruber et al. $[16,17]$ stated that a mattress suture can control the cartilage curvature and provide $35 \%$ increased stiffness and strength. The present author prefers to use either Byrd's or Mustard's suture technique as these suture principles are similar $[3,18]$. Sometimes, two or three additional sutures are needed for reinforcement. Even though deviation is not seen in the external appearance, occasionally septal deformity is found during aesthetic operations. In these

\section{Fig. 1. Septal harvesting}

If the incision line changes its direction, it has to be at a round angle and not a right angle. The remaining small cartilage block can support the power of the remaining L-strut. (A) Illustrations of septum harvesting. (B) Intraoperative view.
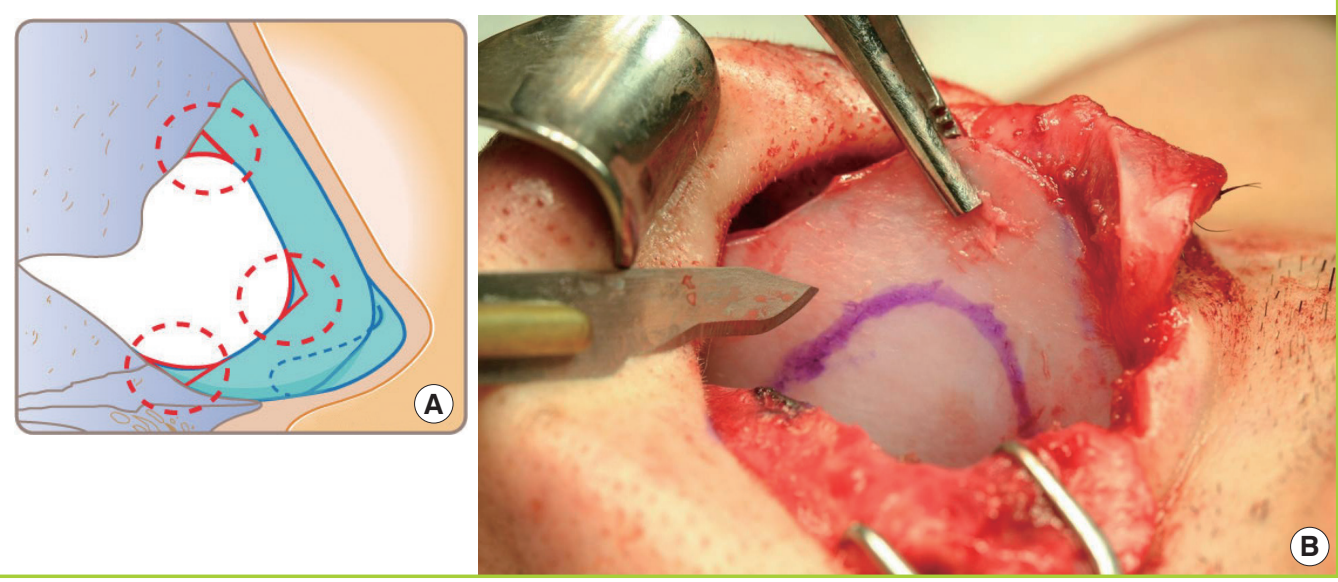


\section{Fig. 2. Stability test of caudal L-strut}

(A) Before stress. (B) The septum tends to flex to one side depending on its property while pushing with forceps posteriorly.
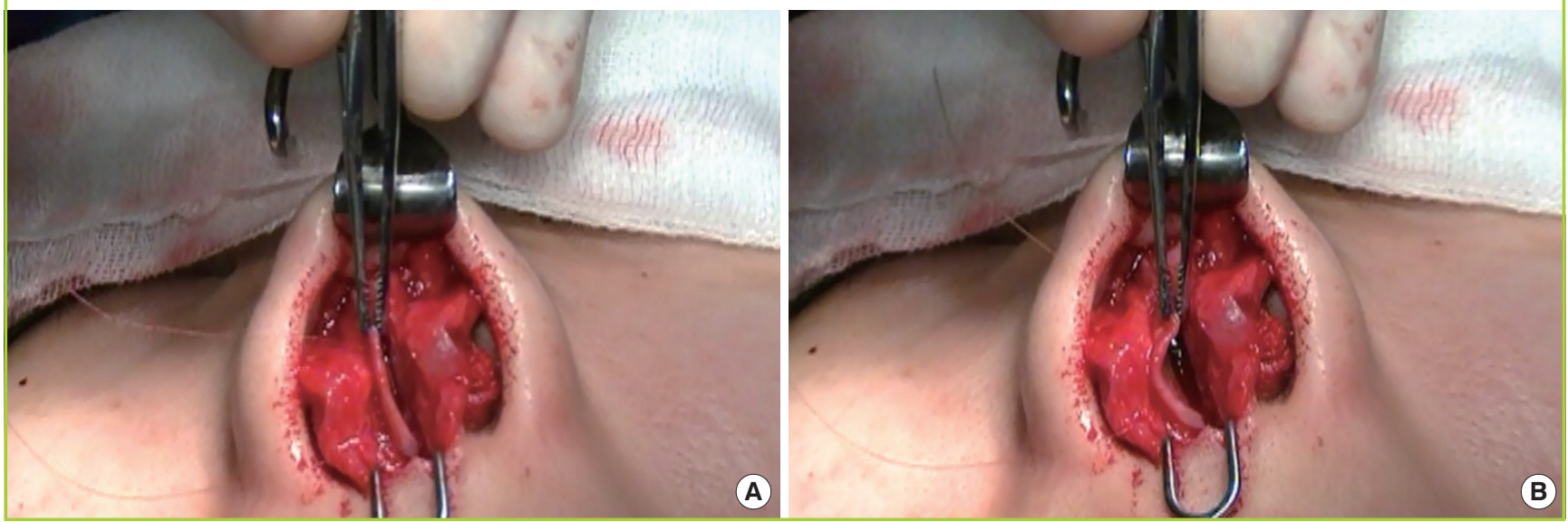

Fig. 3. Intraoperative view of septal deviation

(A) Septal deformity is occasionally found without apparent deviation. (B) Severe intrinsic deviation of the caudal septum is observed after the septal harvest. (C) Strengthening with Mustard's suture technique and extended spreader graft.

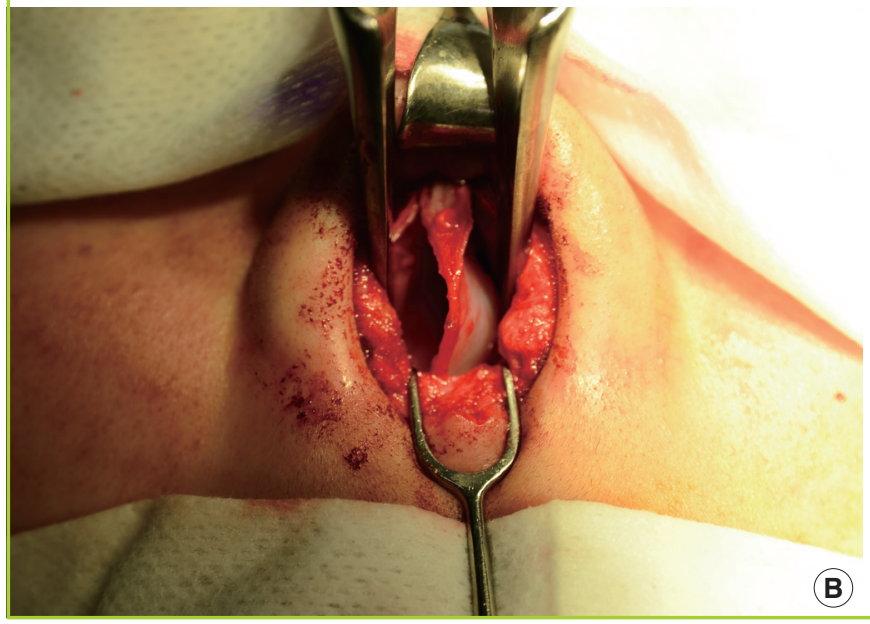

cases, a weakened and flexed septal strut should be reinforced. If the correction is not completed with suture or scoring, an additional supporting graft with cartilage is essential (Fig. 3).

In the case of a short nose, if the caudal septum is extremely short, relying on a single piece of septal graft is improper. The
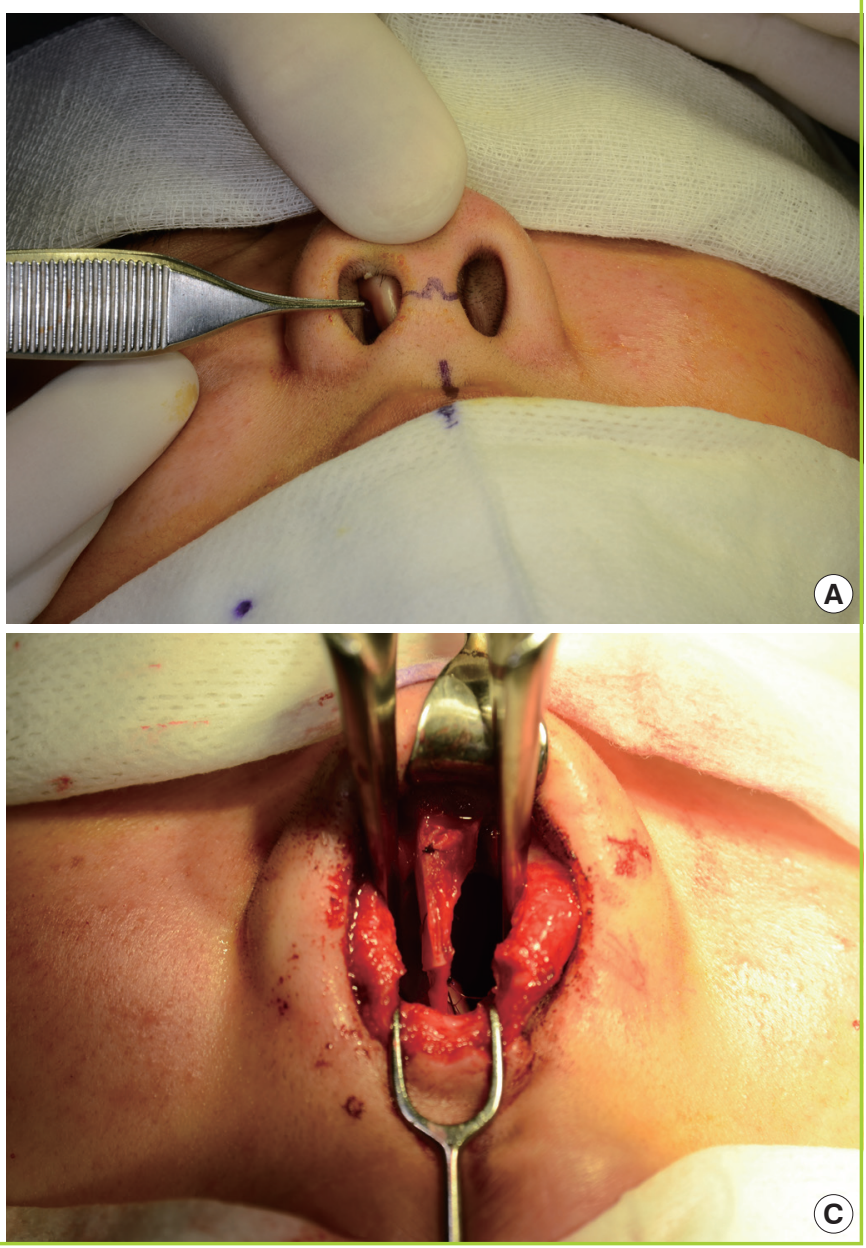

harvested septum should be used for lengthening and reinforcing the dorsal strut by an extended spreader graft. Additional ear cartilage should be consumed for the columellar strut or vertical strut (Fig. 4).

There is controversy as to whether the surgeon should use an 


\section{Fig. 4. Short nose correction using the ear and septum}

(A) Small nose with short caudal septum. (B) Preoperative view. (C) Harvested cartilages (septum and ear). (D) Postoperative view. (E) Operation diagram.
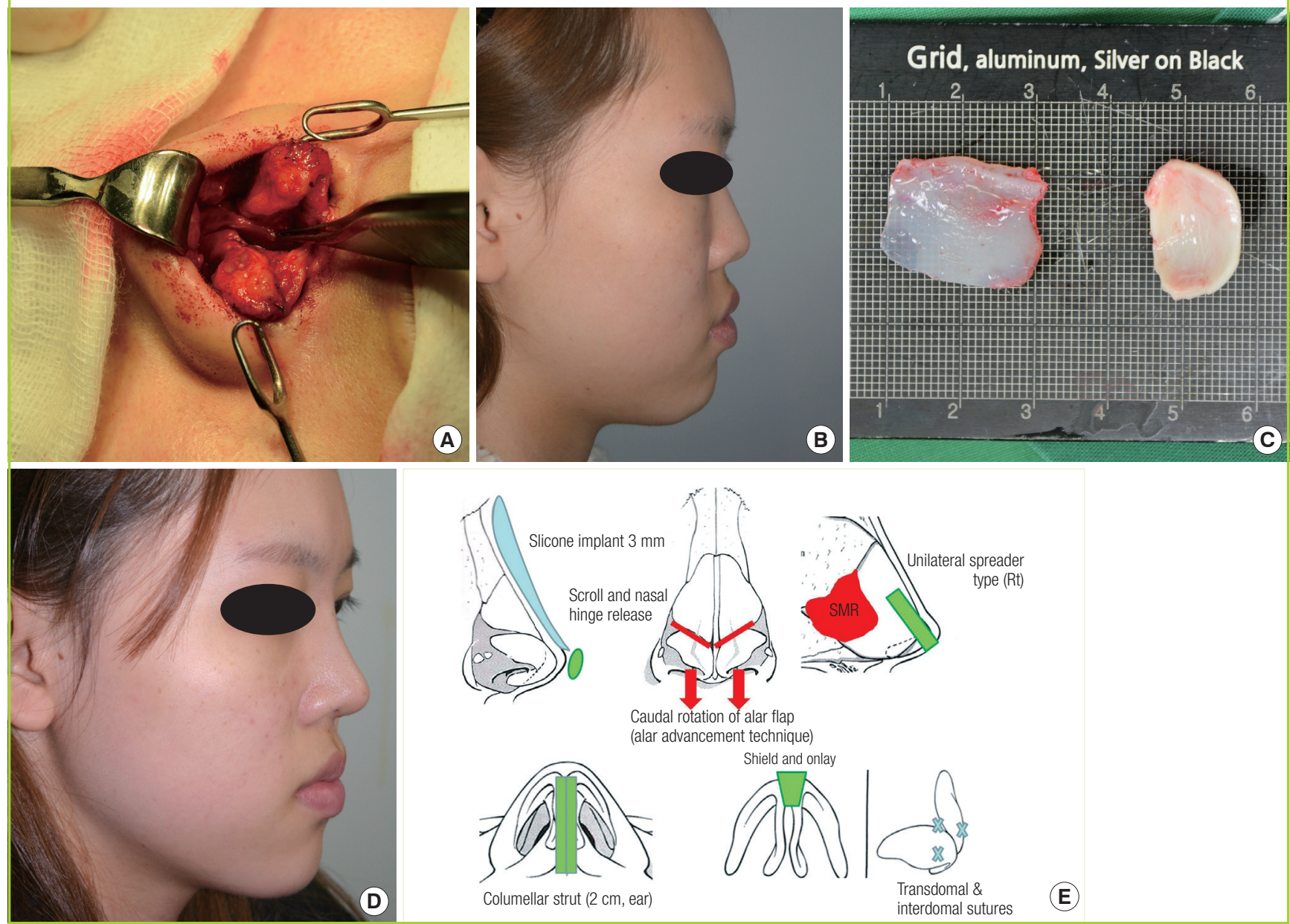

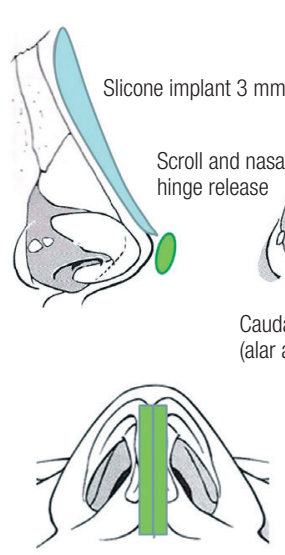

Columellar strut $(2 \mathrm{~cm}$, ear)

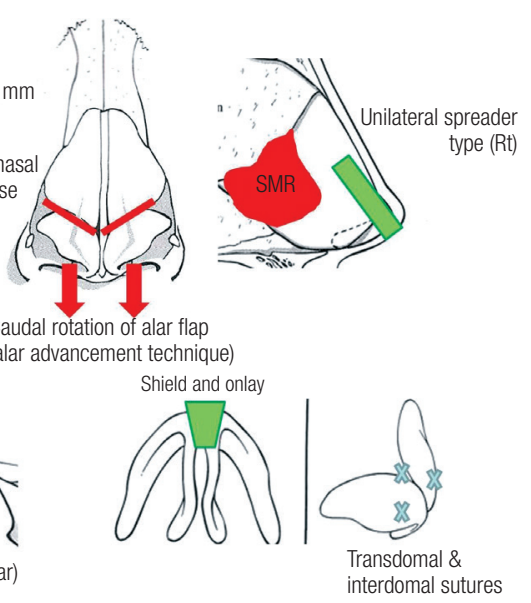

(E)

additional spreader graft or batten graft on the concave side or the convex side in cases of septal strut deviation. However, the method varies among surgeons, and hence, the operator should make an appropriate decision for correction.

\section{Condition of harvested graft}

With respect to the harvested graft, the vomer side is thick, the dorsal strut is relatively thin, and the center part is the thinnest area [9-11]. Owing to this shape, one-third of the inferior part is flexed easily in the cephalocaudal direction during a stress test. The graft design should be made with this in mind (Fig. 5). In cases where the patient has nasal trauma history, a portion of the inferior one-third is the one of the commonest areas of septal deformity or septal fracture. After the cartilage is damaged, volume loss occurs due to apoptosis, making it thinner and weaker, and in turn causing warping and bending $[19,20]$. The reaction to compressive stress varies according to the direction of collagen orientation (anisotropy) [21]. In cases of a single-block cartilage graft for unilateral extension graft, the results depend on the condition of the harvested graft. Even if the patient has had no trauma history, the septum might have already been bent. In this circumstance, a paired or bilateral extension type of graft is more appropriate than a single block type of unilateral extension. The ethmoidal bone can also be sparsely used for adding rigidity and achieving stabilization $[3,14]$.

\section{Stabilizing the nasal base}

The stabilization of the nasal base, which is the lower third of the nose, acts as a foundation stone and is an important factor for determining the position of the alar-columellar relationship and columella-labial angle. If the supporting power is lost, a deformity of the tip shape or position might arise over the long term $[22,23]$.

In particular, in septoplasty, the basal supporting line might be weakened due to the loss of septal integrity in septal-deviated patients, and vomer or maxillary crest lesions have to be corrected simultaneously. A caudal septal repositioning procedure, which entails rigidly fixating the caudal septum to the anterior 


\section{Fig. 5. One-third of the inferior part is flexed easily}

The graft design should be made according to this condition. (A) Harvested septum, before design. (B) Prefabrication of graft.

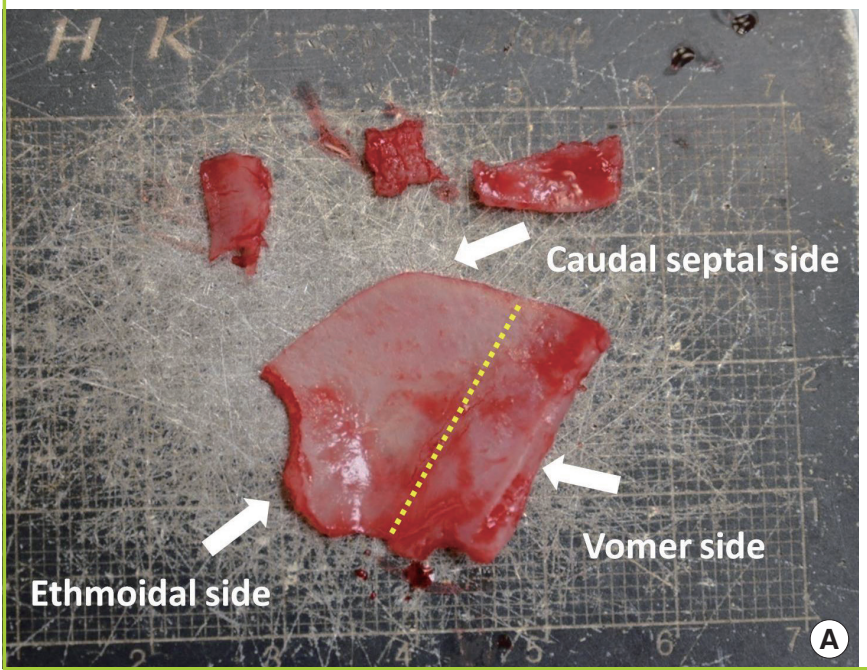

nasal spine, should be performed, since the caudal strut is commonly detached or displaced to the midline after a septoplasty. If the nasal base stabilization is not guaranteed at the anterior nasal spine, a new L-strut reconstruction should be carried out. If the remnant cartilage is weak, an additional cartilage graft such as a batten graft is required. Ear cartilage and rib or irradiated rib cartilages are secondary choices for the graft material $[3,23,24]$.

Preservation of supporting surrounding structures: keystone, upper lateral cartilage, anterior nasal spine, bony septum, and mucoperichondrium

During the elevation of the mucoperichondrium, the mucoperichondrium should not be elevated beneath the keystone in order to lend stability and strength to the keystone area because the perichondrial layer contributes a certain degree of biomechanical strength to the septum $[13,25]$.

Excessively splitting the upper lateral cartilages during septal exposure breaks the dome integrity and therefore, decreases the stability. For the septal harvest, an anterior septal approach caudally is better than the dorsal approach with respect to not dividing the upper lateral cartilage. The cephalic two-thirds of the septum is continuously fused with the upper lateral cartilage and forms a single cartilaginous vault. The distal third is connected with a fibrous attachment [26]. However, the fused septum and upper lateral cartilage might show variable features in each patient. In hump nose correction, excising too much of the upper lateral cartilage might weaken or break the keystone area, and therefore, the surgeon must exercise appropriate caution.

The mucoperichondrium of the septum consists of the mucosa and the perichondrium, which form a composite layer.

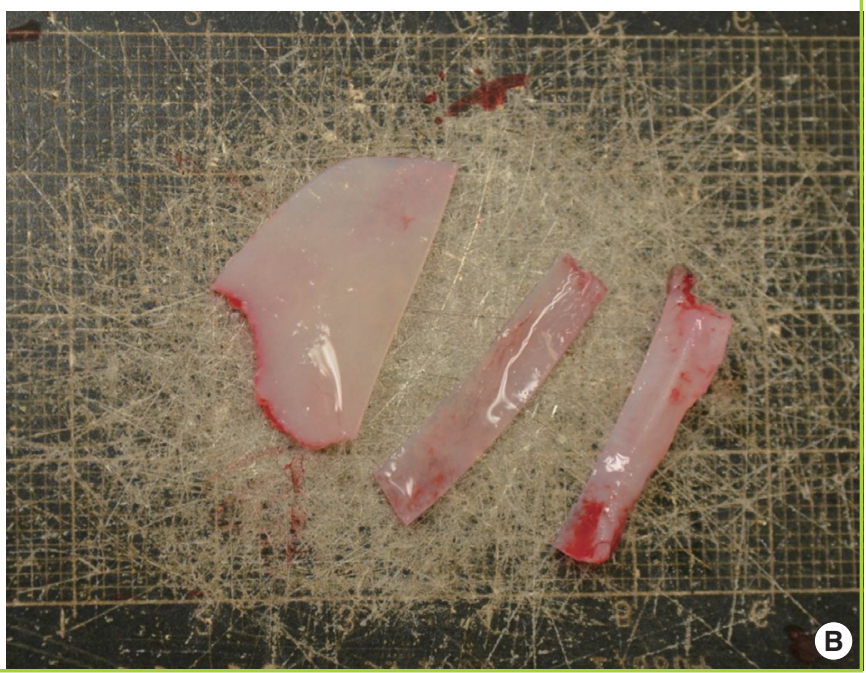

Dissection through the submucosal plane during the harvest is a common inadvertent mistake. This causes not only mucosal thinning but also an increase in the possibility of hematoma formation. It results in the loss of support of the perichondrium and affects the septal stability after the operation. The surgeon is obliged to carry out a submucoperichondrial plane approach after confirmation. Kim et al. [25] reported that the perichondrial layer is the key factor for biomechanical strength. Supplementation of the nasal septal lining prevents complications such as septal perforation.

Although there are variations among patients, the fibrous connective tissue, soft tissue, and some fibers of the depressor septi nasi are usually located at the interspace between the rear of the medial crura of the lower lateral cartilage and the caudal septum. This interspace area is called the "membranous septum." It acts as a shock-resistant medium against external impact and plays an important role in dynamic expression and mobility. Excessive manipulation of this area can be a source of hematoma or scar formation, leading to irreversible scarring.

Because the septal extension graft is widely used, if the membranous septum is damaged or substituted with cartilage, the patient might complain about tip hardness and inconvenience, and this problem is still being explored by researchers [27]. From the perspective of a tip plasty, following the rules of appropriate dissection of the membranous septum and the maximal preservation of this component are critical.

\section{What is the best choice for selecting a graft type?}

The graft types most commonly used by surgeons are the unilateral batten type and the caudal extension type $[1,22,23]$. For these graft techniques, the patient's septal lining should 


\section{Fig. 6. Cadaver models}

Alar mobilization in order to reduce tip tension (during septal graft insetting). (A) The ligamentous structures are visible around the alar cartilage. (B) After scroll release. (C) After nasal hinge release.

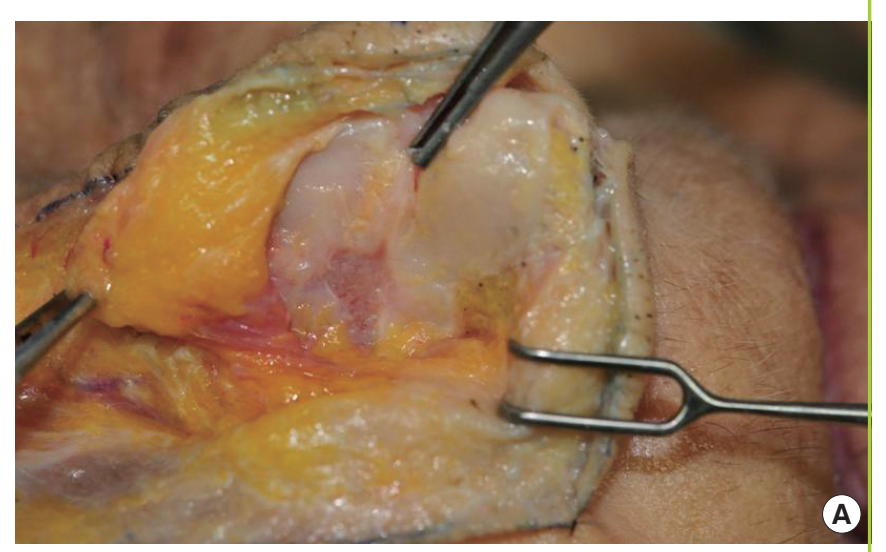

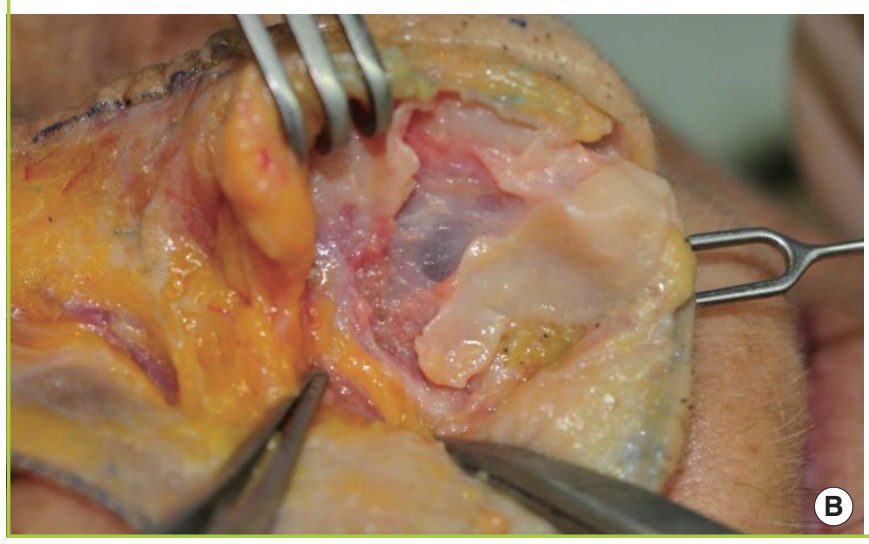

be straight and a large amount of harvested graft is necessary. The caudal septal angle of the recipient site should be rigid and stable. However, in many patients, the L-strut size tends to flex easily in one direction. If the L-strut shifts from the midline or caudally deviates and deflects, the caudal septum deformity should be corrected or the L-strut should be reconstructed. As described earlier, if the septum shows a significant intrinsic deformity, a paired, bilateral caudal extension after septal lining correction should be performed instead of a unilateral extension graft.

Originally, the septal extension graft was an L-strut dependent graft technique. The postoperative tip is influenced by stress factors, such as gravity, pressure of the skin-soft tissue envelope (SSTE), and dynamic action of the facial muscles. To select a graft type, all of these factors should be considered. If nasal lengthening is required for a short nose correction, a spreadertype graft is favorable since it requires extended dorsal strut power. The strength to increase the tip projection might be relatively deficient. The postoperative stress vector that affects the tip SSTE is in the cephalocaudal direction. In order to overcome this, a force columellar strut or vertical-type batten graft should be added. The stress condition to the tip is severe in short-nosed patients, who have thick soft tissue and taut skin. For long-term satisfactory results, an additional graft for the tip support is

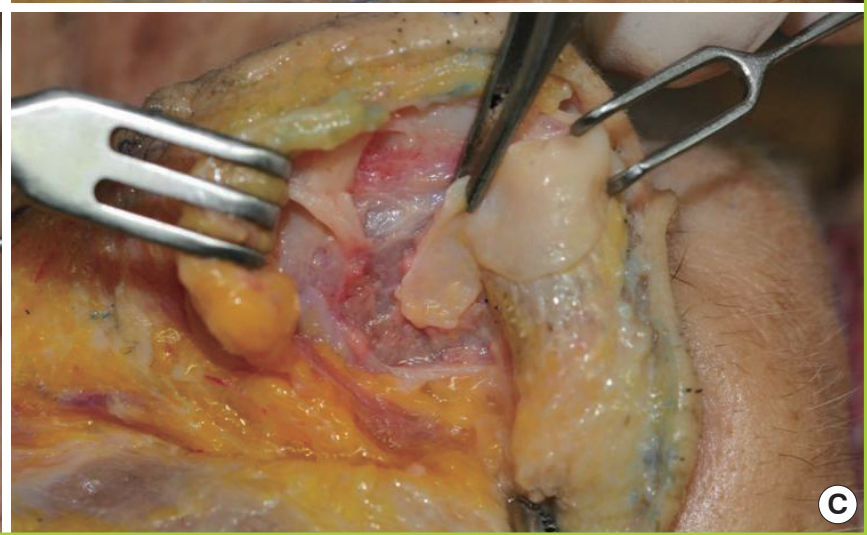

recommended. In cases where there is strong drooping action, an independent strut-type extension or columellar strut will facilitate stability [14]. It is suggested that the surgeon not rely on techniques such as choosing the spreader type or batten type but rather have a flexible operative process under any circumstances and according to the unique factors of each patient.

Release of retaining action: Around the lower lateral cartilages and ligamentous structures

Since the alar cartilage is connected to the upper lateral cartilage and the surrounding ligamentous structures, it must be released softly with minimal tension to anchor the septal extension graft. In particular, in cases of a short nose, the structures attached to an upturned nose or a drooping nose should be sufficiently released, since counter-rotation or rotation arc manipulation is necessary. This maneuver also allows caudal retraction of the lower lateral cartilage without tension (Fig. 6). Removing these retaining actions can yield a stable tip shape. A profound understanding of the anatomical structures is a precondition to prevent excessive manipulation [28-30].

\section{Fixation and insetting}

For caudal septal extension, at least 3-4 mm of the caudal septum and the graft should be overlapped for stable and firm fixation. 

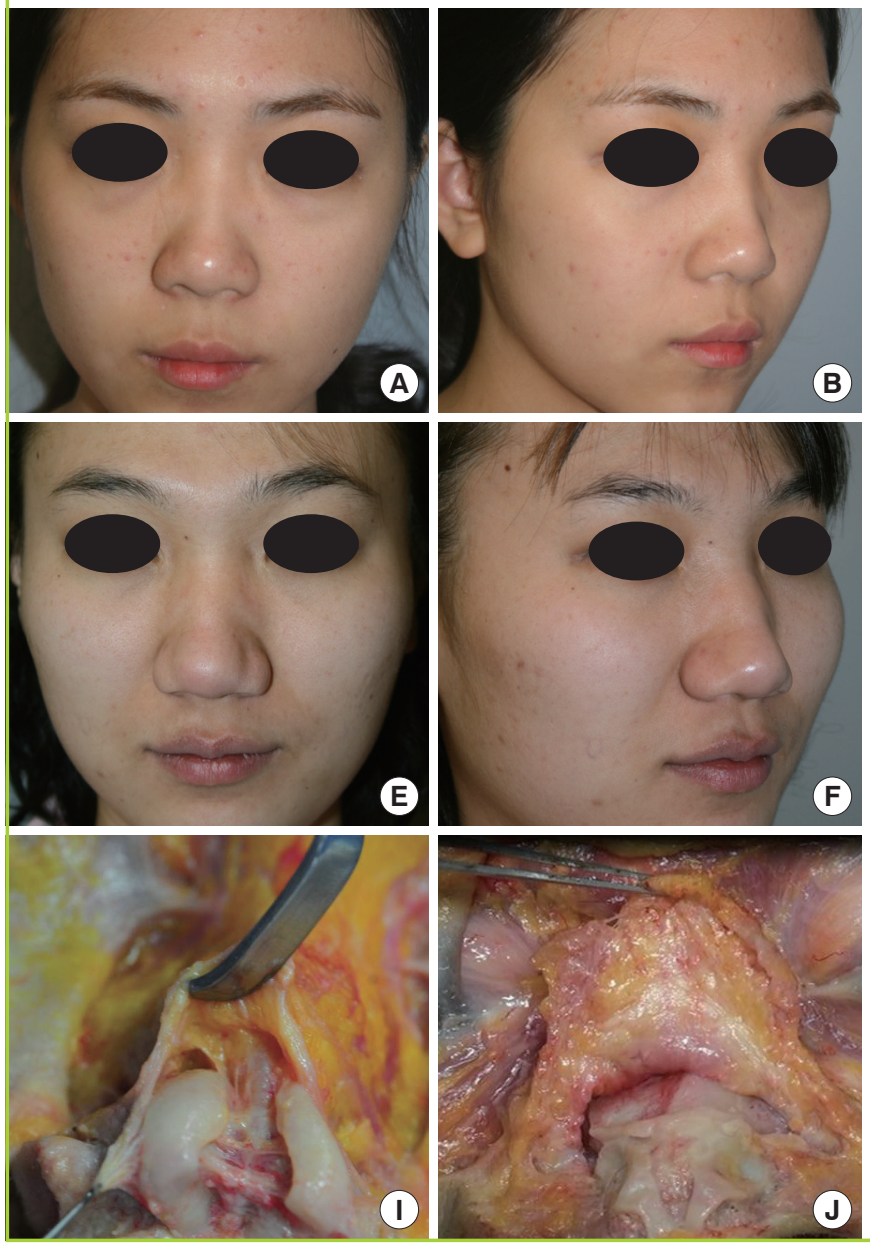

Upper and lower fixation sutures prevent the displacement of the graft $[12,22,23]$. Usually, 3 or 5 fixation sutures are applied between the graft and the septum. However, "up and down" pivot motion occurs during the stability test. In addition to the traditional suture, a pivot locking suture is effective in preventing this "up and down" pivot motion. Rather than the number of fixation sutures, their effectiveness is a more critical factor. Appropriate location, that is, where the L-strut and the graft meet, of the pivot locking suture is helpful in preventing the up and down pivot motion [15]. Usually, nylon or PDS 5-0 is selected for firm sutures between the graft and the L-strut.

Characteristics of the nasal envelope: Resistance to static and persistent stress

In the case of a relatively thick nasal envelope, tip expression is unsatisfactory. The thick envelope exerts constant compression stress to the cartilaginous structures. In particular, the nasal superficial musculoaponeurotic system (SMAS) thickness and characteristics are closely related with the SSTE (nasal envelope) texture and sebaceous contents. A thick SSTE has a thick
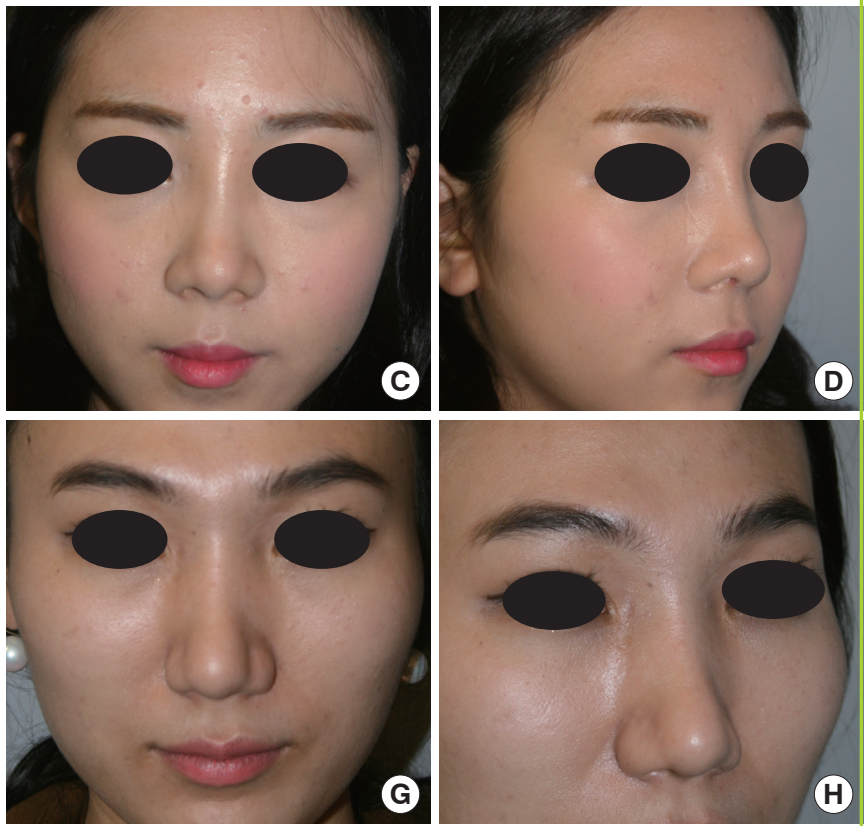

(A-D) Tip definition and surgical control of projection is trouble-free in thin skin-soft tissue envelope (SSTE) patients. (E-H) In contrast, tip definition is difficult in the case of a thick SSTE, and these patients are often unsatisfied with the long-term results. $(I, J)$ From a longterm perspective, the loss of tip projection might occur due to tissue pressure to the tip complex.

SMAS and low elasticity, and the tip shape and definition are poorer than in the case of a thin SSTE (Fig. 7). One of the characteristics of Koreans is that the variation spectrum is extremely wide with substantial nasal envelope thickness. Patients who have a thick layer are often dissatisfied with the operative results [31].

\section{Dynamic component of tip}

Dynamic factors related to tip drooping are the depressor septi nasi muscle inferiorly and the levator labii superioris alaque nasi muscle laterally. The depressor septi nasi is responsible for the tip downward action. Since it acts in a uni-directional manner, its action can be prevented by direct manipulation or a supporting graft. It is difficult to manage the action of the levator labii and other smiling muscles because their actions are lateral tenting [32]. Daily high-frequency stress (talking, eating, smiling, yawning, and so on) can be controlled with a Botox injection postoperatively to the muscles that are around the nose, such as the levators and the smiling muscles. Weakening of these muscles aids initial stable scar modeling after an operation [33]. 


\section{Fig. 8. Neocartilage formation}

A specimen from revision rhinoplasty showed the formation of neocartilage at the septum $\left(H \& E_{1} \times 2.5\right)$.

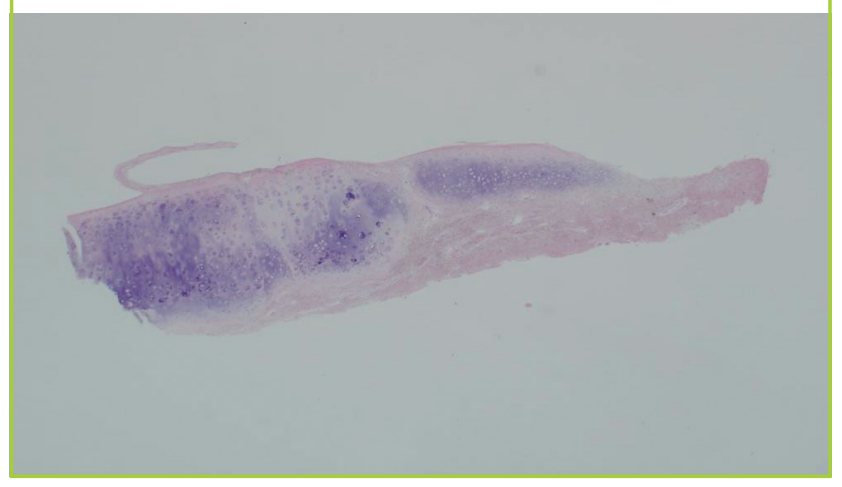

Asymmetric structure and patients' habitual facial movements From a review of previous articles and clinical experience, it has been found that the left side of a woman's face is typically smaller than the right. The bone is also retrograde depressed and soft tissue is relatively thin on the left side [34]. The tip complex shows a similar pattern, but this does not show any correlation with the appearance or the region beneath the cartilage. In general, the caudal septum is altered in less than $50 \%$ of the patients and the anterior nasal spine is changed in less than $5 \%$ [35]. In my experience, several patients have shown caudal septal deviation without significant nasal deviation. This causes tip deviation afterwards, even though the septum is placed at the midline. The different powers of facial muscles and personal habitual actions can deviate the structures progressively.

Does the cartilage regenerate after harvesting the septum? Several studies have reported that the perichondrium is related to cartilage regeneration. Some specimens of the author's revision rhinoplasty cases showed the formation of neocartilage at the septum (Fig. 8). With respect to the donor site, neocartilage also helps the strength, and therefore, mucoperichondrial preservation is critical. Thus, using the neocartilage in rhinoplasty is not recommended. Some other attempts such as using a bioabsorbable plate, PDS foil, and insertion into the donor site are now in progress $[36,37]$.

\section{REFERENCES}

1. Byrd HS, Andochick S, Copit S, et al. Septal extension grafts: a method of controlling tip projection shape. Plast Reconstr Surg 1997;100:999-1010.

2. Ha RY, Byrd HS. Septal extension grafts revisited: 6-year experience in controlling nasal tip projection and shape. Plast Reconstr Surg 2003;112:1929-35.
3. Byrd HS, Salomon J, Flood J. Correction of the crooked nose. Plast Reconstr Surg 1998;102:2148-57.

4. Cardenas-Camarena L, Gomez RB, Guerrero MT, et al. Cartilaginous behavior in nasal surgery: a comparative observational study. Ann Plast Surg 1998;40:34-8.

5. van der Heijden P, Korsten-Meijer AG, van der Laan BF, et al. Nasal growth and maturation age in adolescents: a systematic review. Arch Otolaryngol Head Neck Surg 2008; 134:1288-93.

6. Rotter N, Tobias G, Lebl M, et al. Age-related changes in the composition and mechanical properties of human nasal cartilage. Arch Biochem Biophys 2002;403:132-40.

7. Kim JS, Han KH, Choi TH, et al. Correction of the nasal tip and columella in Koreans by a complete septal extension graft using an extensive harvesting technique. J Plast Reconstr Aesthet Surg 2007;60:163-70.

8. Kim JS, Jang PY, Choi TH, et al. The dimension of the septal cartilage using the cadaver study. J Korean Soc Aesthetic Plast Surg 2006; 12:29-32.

9. Hwang K, Huan F, Kim DJ. Mapping thickness of nasal septal cartilage. J Craniofac Surg 2010;21:243-4.

10. de Pochat VD, Alonso N, Figueredo A, et al. The role of septal cartilage in rhinoplasty: cadaveric analysis and assessment of graft selection. Aesthet Surg J 2011;31:891-6.

11. Mowlavi A, Masouem S, Kalkanis J, et al. Septal cartilage defined: implications for nasal dynamics and rhinoplasty. Plast Reconstr Surg 2006;117:2171-4.

12. Suh MK. Asian rhinoplasty. Seoul: KAPS; 2012.

13. Mau T, Mau ST, Kim DW. Cadaveric and engineering analysis of the septal L-strut. Laryngoscope 2007;117:1902-6.

14. Hubbard TJ. Exploiting the septum for maximal tip control. Ann Plast Surg 2000;44:173-80.

15. Oh SH, Kang NH, Woo JS, et al. Stabilization of unilateral septal extension graft using pivot locking Suture. J Korean Soc Aesthetic Plast Surg 2008;14:156-60.

16. Gruber RP, Nahai F, Bogdan MA, et al. Changing the convexity and concavity of nasal cartilages and cartilage grafts with horizontal mattress sutures: part I. Experimental results. Plast Reconstr Surg 2005;115:589-94.

17. Gruber RP, Nahai F, Bogdan MA, et al. Changing the convexity and concavity of nasal cartilages and cartilage grafts with horizontal mattress sutures: part II. Clinical results. Plast Reconstr Surg 2005; 115:595-606.

18. Calderon-Cuellar LT, Trujillo-Hernandez B, Vasquez C, et al. Modified mattress suture technique to correct anterior septal deviation. Plast Reconstr Surg 2004;114:1436-41.

19. Gorur K, Polat G, Ozcan C, et al. The role of apoptosis in traumatic versus nontraumatic nasal septal cartilage. Plast 
Reconstr Surg 2007;119:1773-6.

20. Holt GR. Biomechanics of nasal septal trauma. Otolaryngol Clin North Am 1999;32:615-9.

21. Richmon JD, Sage A, Wong WV, et al. Compressive biomechanical properties of human nasal septal cartilage. Am J Rhinol 2006;20:496-501.

22. Toriumi DM. New concepts in nasal tip contouring. Arch Facial Plast Surg 2006;8:156-85.

23. Toriumi DM. Structural approach to primary rhinoplasty. Aesthet Surg J 2002;22:72-84.

24. Dhong ES. Septorhinoplasty: endoscopic approach and reinforcement of nasal support line. J Korean Soc Aesthetic Plast Surg 2010;16:111-6.

25. Kim DW, Egan KK, O’Grady K, et al. Biomechanical strength of human nasal septal lining: comparison of the constituent layers. Laryngoscope 2005;115:1451-3.

26. Daniel RK, Letourneau A. Rhinoplasty: nasal anatomy. Ann Plast Surg 1988;20:5-13.

27. Kim JH. Surgical guides for overcoming disadvantages of septal extension geaft in Asians. In: Jeong JY, editor. Proceedings of the Rhinoplasty Symposium Seoul 2009: basic and advanced; 2009 June 21; Seoul: Nine Add Press; 2009. p. 54-7.

28. Han SK, Ko HW, Lee DY, et al. The effect of releasing tipsupporting structures in short-nose correction. Ann Plast Surg 2005;54:375-8.

29. Jeong JY. Tripod framework rebuilding in Asian nose: tip plasty using alar advancement technique. J Korean Soc Aes- thetic Plast Surg 2010;16:125-38.

30. Jeong JY, Yoo YA, Kang NH, et al. expansion procedures of the nasal envelope in short nose deformity: release of the transverse nasalis sling and division of muscle confluence in nasal hinge area. J Korean Soc Aesthetic Plast Surg 2010;16:78-84.

31. Azizzadeh B, Murphy MR, Johnson Jr CM, et al. Master techniques in rhinoplasty. Philadelphia, PA: Saunders; 2011.

32. Oh SH, Choi S, Kim DW, et al. Intranasal approach for manipulating the depressor septi nasi. J Craniofac Surg 2012;23:367-9.

33. Ghavami A, Janis JE, Guyuron B. Regarding the treatment of dynamic nasal tip ptosis with botulinum toxin A. Plast Reconstr Surg 2006;118:263-4.

34. Kim J. The Attractiveness of facial asymmetry in normal population. J Korean Soc Aesthetic Plast Surg 2000;6:16570.

35. Daniel RK, Cox C. Mastering rhinoplasty. 2nd ed. Berlin: Springer; 2010.

36. Han K, Yeo HJ, Choi TH, et al. Rhinoplasty using Various Autogenous Tissues. J Korean Soc Plast Reconstr Surg 2010;37:37-45.

37. Boenisch M, Tamas H, Nolst Trenite GJ. Morphological and histological findings after typical surgical manipulations on growing septal cartilage in rabbits. Facial Plast Surg 2007;23:231-7. 